\title{
A ESCOLA INTERCULTURAL INDÍGENA NA COLÔMBIA E NO BRASIL DESDE 0 PONTO DE VISTA DA LITERATURA ANTROPOLÓGICA: INSTRUMENTO CIVILIZATÓRIO OU INSTRUMENTO POLÍTICO INDÍGENA?
}

MAURICIO CAVIEDES ${ }^{1}$

UFRGS

\begin{abstract}
RESUMO: Este artigo propõe discutir o problema da dominação de uma sociedade sobre outras e a sua ligação com o conhecimento escolar. Essa discussão é necessária para os povos indígenas conseguirem o direito de ter uma educação que garanta sua sobrevivência, com acesso aos conhecimentos chamados de "universais", mas também com respeito aos conhecimentos chamados de "próprios" ou "tradicionais". Com o propósito de achar uma solução para esse problema, este artigo apresenta os avanços nos estudos sobre a educação indígena na Colômbia e no Brasil entre as décadas de 1990 e 2000. Sobre essa apresentação, cria uma classificação dos autores: aqueles que enfatizam as consequências civilizatórias da escola sobre os povos indígenas e os que enfatizam o processo de reinterpretação e apropriação indígena da escola. A classificação não procura criar uma dicotomia, mas servir como instrumento analítico dos pontos de vista dos antropólogos e antropólogas sobre o assunto. Além disso, essa classificação pode ajudar os povos indígenas na construção de instrumentos (escolares ou não) para formar os futuros líderes políticos dos seus povos.
\end{abstract}

PALAVRAS-CHAVE: etnologia indígena; Colômbia; Brasil; educação indígena.

ABSTRACT: This article discusses the problem of the subordination of a culture to another and the role of schools in such subordination. That debate is necessary for indigenous peoples to achieve a system of education to grant their survival as indigenous peoples, transmitting them the so called "universal" knowledge, but also protecting the "traditional" indigenous knowledge. This article presents the developments in anthropological research on that subject in the decades of 1990 and 2000, with the aim of finding a solution to that problem. Based on the literature review, this article classifies authors between those who study the civilizational effects of indigenous schools, and those who study the indigenous reinterpretation of schools in favor of their struggles. This classification does not seek to reduce, but to explain the differences in the points of view of the authors reviewed. This classification may also help indigenous peoples in creating instruments to educate their young leaders, inside or outside schools.

KEYWORDS: ethnology; Colombia; Brazil; indigenous education.

\footnotetext{
${ }^{1}$ Mauricio Caviedes é pós-doutorando do PPGAS da Universidade Federal do Rio Grande do Sul, desde outubro de 2015. Possui graduação em Antropologia (2001), Mestrado em Antropologia (2004) e Doutorado em História pela Universidad Nacional de Colombia. Integra o Núcleo de Antropologia das Sociedades Indígenas e Tradicionais (NIT) do departamento de Antropologia da UFRGS. E-mail: mauriciocaviedes2009@gmail.com.
} 


\section{Introdução}

A educação indígena dentro e fora da escola tem sido muito importante na defesa dos direitos dos povos indígenas, embora a literatura antropológica tenha dedicado maior atenção à defesa do território e à participação política. Sem dúvida, a educação faz parte de uma luta que tem a defesa do território no seu centro. No entanto, vários autores da Colômbia e do Brasil vêm buscando demonstrar que o papel da educação na sobrevivência dos povos indígenas não é secundário (D'ANGELIS, 2012; CORREA, 2015; TATTAY BOLAÑOS, 2010).

Porém, a defesa da educação indígena tem valor para a defesa dos direitos indígenas e de outros setores sociais. A luta pelo direito dos povos indígenas de ter uma educação que permita a sua sobrevivência faz parte de um propósito maior: a rejeição da imposição das formas de pensamento de origem europeia sobre as dos outros povos. Segundo antropólogos como Eric Wolf (1982), Kuper (2002) e Rosaldo (2000), essa imposição é resultado dos esforços para justificar a dominação política, militar, ideológica e econômica.

Além disso, dentro dos países da América Latina existe uma relação de dominação sobre os povos indígenas da sociedade que pensa fazer parte da chamada "civilização europeia", e que poderíamos chamar de "nacional" (ou "mestiça"). Como afirmou o sociólogo Christian Gros, essa relação foi nomeada de "colonialismo interno" por alguns cientistas sociais durante a década de 1970 (GROS, 1991).

No entanto, muitos antropólogos vêm buscando demonstrar que essa dominação histórica não é resultado de uma fraqueza no conhecimento indígena, nas formas de organização social ou econômicas baseadas nesses conhecimentos. Levi-Strauss (1992 [1967]) parece ser quem mais contribuiu para demonstrar esse argumento, mas vários outros contribuíram desde o começo da disciplina, segundo afirma Kuper (2002).

É por isso que a antropologia e a ciência têm uma dívida com o estudo da educação escolar e não escolar entre os povos indígenas.

Para avançar nesse estudo, sugiro classificar as hipóteses sobre 
educação indígena na antropologia do Brasil e da Colômbia da seguinte forma: de um lado, chamarei "contraescolares" os estudos que enfatizam as consequências civilizadoras das escolas sobre os povos indígenas e, do outro lado, chamarei "reinterpretacionistas" os que enfatizam a forma dos indígenas reinterpretarem a escola em prol das suas lutas. Essa classificação está baseada na análise da literatura antropológica escrita desde a década de 1990 até hoje em ambos os países. No entanto, não apresento aqui dados e ideias de todos os autores, porque a extensão do artigo o impede. Apresento uma seleção de trabalhos que acho influentes e representativos.

Essa classificação não é ainda rigorosa, mas é uma proposta para ajudar na compreensão das diferentes formas de entender a escola desde a antropologia. Faço essa advertência para explicar ao leitor que nenhum dos autores cujas ideias apresento aqui aceitaria fazer parte dessas categorias. Qualquer um deles (ou delas) admitiria que a escola tenha sido um instrumento colonizador imposto pelas igrejas e pelos governos, embora atualmente tenha sido transformada e utilizada pelos povos indígenas na defesa dos seus direitos. É preciso entender que a dominação da sociedade nacional não impede os esforços dos povos indígenas para sobreviver. Assim como convém diferenciar os estudos que colocam o foco sobre o papel civilizador e integrador da escola daqueles que enfatizam o uso indígena da escola contra a colonização.

Por que é importante fazer essa diferenciação?

Se acreditarmos que a escola ainda tem um papel colonizador, embora tenha sido reinterpretada pelos povos indígenas para as suas lutas, então precisamos atingir os mecanismos colonizadores para eliminá-los. Nesse caso, estamos procurando uma solução que ainda não existe e precisa ser criada. Considerando que se os povos indígenas estão reinterpretando e apropriando-se da escola em prol dos seus direitos, então precisamos entender como o fizeram, para que possamos apoiar tais processos onde sejam fracos ou incompletos. Assim sendo, esse conhecimento nos auxiliaria a continuar um processo já iniciado.

A classificação que apresento, portanto, não está acabada, mas visa entender melhor esses processos em vez de criar uma dicotomia. No entanto, acredito que expor essa classificação pode ajudar também 
na forma de uma síntese que abre discussões e debates.

\section{Debates centrais presentes na antropologia clássica}

Talvez o problema mais importante no início dos trabalhos da antropologia foi o problema do funcionamento do conhecimento chamado de "selvagem". Durkheim comparou o conhecimento dito "primitivo" com o europeu, quando afirmou que ambos compartilhavam o instrumento de classificação presente em todas as formas de conhecimento, desde aquelas chamadas "primitivas" até as "desenvolvidas" (DURKHEIM, 1992 [1912]). Inspirado nessa ideia, Malinowski sugeriu que as formas de organização social e econômica indígenas não eram mais simples do que as europeias. No seu livro póstumo sobre a mudança cultural, Malinowski defendeu o direito das culturas tradicionais africanas de continuarem existindo e afirmou que o governo britânico deveria garantir a "autonomia administrativa" dos povos indígenas para diferentes propósitos. Um deles era a educação (MALINOWSKI, 1949).

Assim, segundo Malinowski, enquanto a administração da educação estiver nas mãos dos povos indígenas, a hierarquia política do conhecimento europeu não poderia impedir a existência do conhecimento indígena.

Porém, na década de 1980, Richard Musgrove estudou a contradição dos povos indígenas africanos ao ensinar as línguas e os costumes indígenas na escola. $O$ antropólogo britânico afirmou que a escola é o único instrumento para formar líderes que possam falar pela comunidade com o sistema político dominante. Portanto, no momento em que os conhecimentos indígenas chegarem à escola, eles perderiam significado, porque precisam da vida cotidiana para serem ensinados (MUSGROVE, 1982). Logo, a única solução seria limitar a escola para o ensino do conhecimento dominante (MUSGROVE, 1982).

De outro lado, a tese principal da antropóloga Margaret Mead era de que não existia um processo universal de crescimento intelectual e, por isso, não poderia existir um processo de aprendizado relacionado com a idade. A metodologia de pesquisa, baseada na comparação, 
levou-a a afirmar que era possível uma educação baseada na mistura de conhecimentos de diferentes sociedades (MEAD, 1949 [1928]; BATESON, 2004). Por isso é possível propor que a defesa da "interculturalidade" foi originada por Margaret Mead.

Origem das ideias sobre educação indígena na antropologia do Brasil e da Colômbia

Para Tassinari, existem três momentos diferentes do estudo da educação na história da antropologia Brasileira no século XX. Na década de 1930, durante a formalização dos estudos antropológicos no Brasil, a antropologia se afastou de ideias evolucionistas do começo do século XX, mas aceitava que a educação deveria ser instrumento de integração dos povos indígenas na cultura nacional. $O$ olhar dos antropólogos brasileiros sobre os povos indígenas e sua educação foi se modificando desde a década de 60 até o final dos anos 80 , em uma posição crítica à política do Estado brasileiro, ao mesmo tempo em que os antropólogos contribuíram para se catalogar as populações indígenas e definir estratégias de atuação sobre a relação desses povos com o resto da sociedade brasileira. Apenas com a promulgação da Constituição federal de 1988, com acompanhamento de alguns antropólogos, é que as políticas públicas brasileiras reconheceram os princípios da Convenção 169 da Organização Internacional do Trabalho (OIT), a diversidade cultural dos povos indígenas e seus processos próprios de aprendizagem (TASSINARI, 2009).

Porém, segundo outros autores, a substituição do Serviço de Proteção aos Índios (SPI) pela a Fundação Nacional do Índio (FUNAI) e outras mudanças semelhantes da política brasileira só foram instrumentos de defesa do regime militar contra a crítica internacional. Lima, Barrero-Hoffman e Peres (s.d.) afirmam que as ideias antropológicas que guiaram o SPI mudaram só de aparência na FUNAI. Essa mudança procurava evitar críticas internacionais que ameaçavam o apoio financeiro internacional almejado pelo regime para a expansão do desenvolvimento na Amazônia.

Mas a combinação de um novo modelo de formação acadêmica na 
antropologia, a criação de ONGs por intelectuais formados nesse modelo e a influência das ideias de "etnodesenvolvimento" de intelectuais na América Latina criou um novo tipo de ação indigenista e levou novas ideias à Constituição de 1988. Infelizmente, as mudanças ficaram no nível formal, mas ainda são fracas no nível local (LIMA, BARROSO-HOFFMAN e PERES, s.d.). A ausência dessas propostas é evidente no ensino escolar e nos conteúdos dos materiais de ensino sobre e para os povos indígenas, mas também na política e administração pública dos direitos dos povos indígenas (GOBBI, 2012).

No caso da Colômbia, o processo parece similar. As políticas de educação do século XX para os povos indígenas tinham a finalidade de "civilizá-los". Essa política continuou até a década de 1970, quando as organizações indígenas exigiram, em 1971, a criação de políticas de educação bilíngue e a contratação de professores indígenas nos seus territórios. Em 1978 a lei mudou para permitir a contratação de professores indígenas. Mas só com a Constituição de 1991 é que o governo reconheceu o direito dos povos indígenas de decidirem o conteúdo do ensino de suas escolas. Embora existam leis que reconhecem esses direitos, ainda hoje as dificuldades administrativas impedem os povos indígenas de decidir os conteúdos do ensino escolar. No caso da Colômbia, existiu também uma influência forte das ideias dos intelectuais mexicanos R. Stavenhagen e G. Bonfil Batalla sobre os antropólogos que trabalharam com organizações que exigiram o direito dos povos indígenas para construírem sua educação (CASTELLANOS e CAVIEDES, 2007).

No entanto, não parece possível dizer que essas mudanças tenham sido simplesmente o resultado do desenvolvimento de uma crítica desde a antropologia, ou de um desenvolvimento dos movimentos indígenas. No Brasil, bem como na Colômbia, várias das primeiras experiências de educação escolar e educação bilíngue foram resultado da influência do Summer Institute of Linguistics (SIL). Essas formas de educação foram criadas também com propósitos civilizadores, segundo sugere D'Angelis ao explicar as bases históricas da educação indígena no Brasil (D'ANGELIS, 2012, p. 23-24). Gros (1991) e Vasco (2002, p. 159-164) explicam a influência do SIL no caso dos indígenas da Amazônia e a região dos Andes colombianos. 
Em palavras mais simples: 1. As lutas indígenas mudaram a opinião da antropologia; 2. Os antropólogos e os indígenas influíram nas políticas públicas para a educação indígena contra uma educação civilizadora; 3. No cotidiano, a educação nos territórios indígenas ainda está na contradição entre "civilizar" os povos indígenas para fazerem parte da sociedade nacional e fortalecer suas tradições.

Então, vale a pena perguntar como as pesquisas antropológicas explicam a relação dos povos indígenas com a escola.

\section{Escola: colonização ou liberação?}

Embora as pesquisas geralmente aceitem que nas escolas indígenas existem sempre processos de apropriação e "civilização" ou colonização do conhecimento, alguns pesquisadores dão maior atenção ao processo de apropriação e outros ao processo de colonização.

D'Angelis sugere que as políticas de educação indígena do governo brasileiro na década de 1990 ainda compartilhavam a filosofia colonizadora do SPI e não procuravam acabar com a submissão dos povos indígenas. Pelo contrário, propõe, as leis tinham uma perspectiva integracionista e etnocêntrica. Para D'Angelis, a ideia de que a escola é necessária porque só a educação e o conhecimento escolar são úteis para as crianças indígenas é prova dessa política colonizadora (D'ANGELIS, 2012, p. 46).

Segundo D'Angelis, não se trata de negar o acesso às escolas para os povos indígenas, mas é necessário duvidar da ideia de que o ensino escolar deve ser induzido sob os princípios individualistas de liberdade. Nesta abordagem, D'Angelis (2012, p. 227) acha que a escola chamada de "diferenciada" disfarça uma política colonizadora. Pelo contrário, a escola deveria ser um espaço de luta de classes, de disputa dialética de valores culturais, de resistência cultural baseada na avaliação das formas do pensamento indígena em disputa com as formas do pensamento chamado de "universal" (D'ANGELIS, 2012, p. 228). Assim, D'Angelis estabelece uma diferença entre as possibilidades e a realidade da escola.

De forma semelhante, Vasco propõe uma educação baseada no 
aceite das contradições visíveis entre o conhecimento chamado de "universal" e as formas do conhecimento indígena como alternativa à política da educação "intercultural". Para o autor, a educação "intercultural" é um engano, pois é imposta apenas aos povos indígenas, que devem aprender os seus conhecimentos e os da sociedade em geral, enquanto esta só aprende o conhecimento "universal". O autor acredita que essa política de educação não reconhece os processos históricos que levaram os povos indígenas até uma situação de subordinação política e econômica (VASCO, 2002, p. 163).

Entretanto, além da desigualdade histórica, existe uma incompatibilidade entre alguns elementos do conhecimento indígena e o conhecimento escolar. Jackson ilustrou essa incompatibilidade na década de 1990, pouco depois da aparição das leis que reconheciam a possibilidade de incorporar conteúdos indígenas no currículo escolar. Nesse momento, os xamãs indígenas do Vaupés, na Amazônia colombiana, rejeitavam ensinar elementos do conhecimento tradicional nas escolas, pois, na tradição indígena da região, esses conhecimentos deveriam ser recebidos na maloca. Ensinar esses conhecimentos seria apresentar a tradição fora do seu contexto e isso tornaria impossível entendê-Ios (JACKSON, 1995).

De outro lado, existem autores que apresentam uma crítica às escolas nos territórios indígenas, mas enfatizam os esforços dos povos indígenas na apropriação das escolas, para lhes dar um novo significado, mais harmônico com a sua história e com o propósito da sua continuidade histórica.

Para alguns autores, a escola é necessária para os povos indígenas apropriarem-se dos instrumentos da sociedade brasileira para as suas lutas. A escola é um espaço para os povos indígenas formarem os seus líderes. Tudo isso é necessário para os povos indígenas conseguirem a sua autonomia. Para esses autores, o estudo da educação indígena deve ajudar na participação democrática desses povos. Mas deve ajudar, também, a entender os limites da intervenção pedagógica nas comunidades indígenas (ALBUQUERQUE e GRANDO, 2012).

Vários autores admitem que aprender como próprios os instrumentos da cultura "dominante" traz uma dificuldade importante. Tassinari utiliza a análise da criação de escolas indígenas no Uaçá para 
entender as dificuldades do processo de apropriação indígena da escola (TASSINARI, 2001).

A autora ressalta a participação das famílias indígenas no processo de criação de suas escolas. Para a autora, as famílias locais e a comunidade entenderam as escolas como lugares de criação, articulação e transmissão de conhecimentos. Segundo afirma, ainda, as escolas indígenas não são simplesmente formas impostas de educação, porque os indígenas criam novos significados para a escola nos seus territórios (TASSINARI, 2001).

No entanto, existem diferentes formas de apropriação da escola, segundo Tassinari. Os povos indígenas que foram educados nas escolas convencionais tiveram uma geração de novas lideranças formadas que, depois de serem educadas, encontraram na identidade indígena um instrumento para negociar seus direitos com o governo do Brasil. Mas esses povos e suas lideranças acham que a educação os afastou das suas tradições e devem resgatá-las procurando os ensinos das pessoas mais velhas da comunidade, com o propósito de valorizar a tradição. Dessa forma, podem ter uma identidade autêntica, embora a tradição e a história que devem resgatar sejam heterogêneas. É por causa dessa situação que, em alguns territórios indígenas, a comunidade rejeita a escola diferenciada.

A autora explica essa dificuldade como uma lacuna criada pela mudança entre as políticas de educação para "civilizar" os índios e a política de educação diferenciada (TASSINARI, 2001, p. 190-191). Conforme sugere, os povos indígenas são valorizados apenas se mostrarem uma tradição de acordo com os preconceitos sociais estabelecidos sobre eles. Por isso, os indígenas formados no contexto de políticas de educação civilizadoras não conseguem aceitar a escola diferenciada, que, por sua vez, ainda parece procurar a civilização dos povos mais tradicionais. A autora afirma que, no contexto da educação indígena, as palavras "tradição" e "cultura" não têm um significado claro e, por isso, não parecem se relacionar com a vida cotidiana indígena (TASSINARI, 2001, p. 191).

Esta perspectiva ressalta a participação dos povos indígenas na construção das escolas, mas não esconde as contradições entre a educação escolar civilizadora e a educação diferenciada. 
Numa coletânea recente, Tassinari apresenta um estado da arte sobre as concepções da educação e da infância na antropologia. Segundo a autora, a antropologia ainda não consegue relacionar os estudos dos problemas cotidianos da escola e os estudos da noção de pessoa e a cosmologia (TASSINARI, 2012a). Isso leva à pergunta sobre o contexto de apropriação das escolas indígenas.

$\mathrm{Na}$ mesma coletânea, Tassinari e Cohn analisam os problemas da educação diferenciada no Brasil baseadas em duas experiências que parecem contrárias: de um lado, o modelo de escola assimilacionista apropriado como estratégia de relacionamento com a sociedade não indígena pelos Karipuna do Uaçá; do outro lado, o modelo de escola não diferenciada aceito pelos Mebengokré-Xikrin, um povo monolíngue. Nesse contexto, apresentam a interpretação indígena da escola como instituição e o conceito de "fronteira", para explicar a apropriação indígena da escola, apesar das dificuldades criadas pela lei para a participação indígena nas políticas educativas.

As autoras sugerem que, embora seja possível ensinar os conhecimentos locais na escola, isso é pouco experimentado, porque as propostas de escolas diferenciadas ainda reproduzem o modelo tradicional de escola "ocidental", que reduz a importância dos conhecimentos locais ou "étnicos". Para elas, a escola foi aceita entre os Karipuna e os Mbengokré-Xikrim como um valor e não como um problema, porque faz parte da "Abertura ao Outro". Isso permitiu que a política de educação diferenciada mudasse da assimilação à valorização da cultura indígena (TASSINARI e COHN, 2012, p. 266).

Por isso, segundo as autoras, o "indígena" e o "não indígena" não precisam ser entendidos como duas unidades fechadas e opostas e, ao contrário, podem ser entendidos como uma situação de interação e comunicação entre diferentes. Dessa forma, a escola não é só imposição ocidental, nem só apropriação e domesticação indígena por uma instituição externa. A escola é, então, um espaço onde conhecimentos indígenas e não indígenas se encontram e tentam se comunicar. Por isso, as escolas são uma fronteira entre o indígena e o não indígena, fronteira de negociação entre práticas e saberes (TASSINARI e COHN. 2012, p. 267).

Além da ideia de fronteira, conforme Tassinari, a escola produz 
um tipo específico de infância (TASSINARI, 2012b, p. 275). Mas a escola não é o único lugar para as crianças, que não devem estar afastadas de outros espaços da sociedade onde também aprendem. A autora não procura reduzir a importância da escola, senão criticar a ideia da escola como único instrumento de ensino e único espaço das crianças na sociedade (TASSINARI, 2012b, p. 277). Por isso, ressalta o esforço dos povos indígenas de manter formas de educação fora da escola.

Alguns autores na Colômbia parecem compartilhar a tese da reinterpretação da escola entre os povos indígenas. Rojas Curieux apresenta a criação do alfabeto da língua dos indígenas nasa, na região do Cauca colombiano, como um exemplo dos processos de reinterpretação dos conhecimentos não indígenas em prol das lutas dos povos indígenas. O povo Nasa utilizou a língua espanhola na escrita desde a colonização hispânica para lutar pelos seus territórios. A consciência dessas formas de luta inspirou um grupo de pesquisadores, inclusive pesquisadores indígenas, a criar o alfabeto utilizado hoje nas escolas indígenas, no território do povo nasa, para o ensino das línguas nativas (ROJAS, 2005).

Em um artigo recente, Santiago Gutiérrez apresenta como engenhosas as experiências das organizações indígenas nos andes colombianos para criar novas alianças políticas e étnicas e para administrar o sistema educativo diante das mudanças da lei daquele país. Essas alianças exigem novas formas de representação étnica e política de povos que, até poucos anos atrás, falavam de si mesmos como diferentes e até antagônicos (GUTIÉRREZ, 2015).

$\mathrm{Na}$ mesma abordagem, depois de estudar as diferentes formas dos povos indígenas entenderem a escola na Amazônia colombiana, Mahecha sugere que os povos indígenas amazônicos entendem a aprendizagem escolar como uma atividade semelhante à atividade xamânica. Para os povos amazônicos, segundo Mahecha, a leitura e a escrita são atividades xamânicas dos "brancos". A relação com o papel por meio da leitura, a escrita e o dinheiro são características das formas de poder, dos conhecimentos e das relações da sociedade "branca" com outras sociedades. Essa representação xamânica da relação da escola com a escrita é a causa dos xamãs prepararem as crianças antes de elas irem para a escola. A preparação do xamã deve ajudar a criança a 
aprender e evitar os perigos de estarem fora da comunidade e de utilizar a "bruxaria do branco" (MAHECHA, 2006).

Mas o dilema da escola como instrumento de colonização ou instrumento apreendido não está resolvido na literatura antropológica. Uma das razões é o papel da escola e da educação nas lutas políticas dos povos indígenas na América Latina e o papel da escola na relação entre a sociedade nacional dominante e os povos indígenas.

Susana Cavalheiro de Jesus estuda os problemas da política de educação para os Mbyá-Guarani desde o ponto de vista político, nos acampamentos no sul do Brasil. A autora explica em seu artigo que a posição entre os Mbyá-Guarani sobre a educação é de que a escola faça parte de um programa maior que devia começar com a titulação das terras para os Mbyá-Guarani no sul do Brasil. Propõe que é preciso entender o ponto de vista dessa etnia sobre a escola e a educação para conseguir uma política educativa. No entanto, para o governo estadual e para a administração municipal, a educação e a política escolar é um projeto sem relação com os outros problemas políticos daqueles indígenas. Ao estudar essa contradição, conclui que é preciso levar em conta que para os Mbyá-Guarani a escola não é o mesmo tipo de escola que imaginam as pessoas não indígenas. A autora explica também que, para os Mbyá-Guarani, a escola é um espaço de relacionamento entre as crianças para a sua formação, mas não simplesmente para a formação dos conhecimentos, senão também para a formação de corpos saudáveis em relação com a terra e com o território. Esse relacionamento é o que permite desenvolverem seus corpos (JESUS, 2014).

Uma ideia semelhante é apresentada por Albuquerque e Nakashima (2012), no seu texto sobre as políticas de educação para os Pankararu migrantes na cidade de São Paulo. Nesse processo, o reconhecimento dos direitos dos povos indígenas nas cidades virou uma dificuldade para as instituições indigenistas, principalmente a FUNAI, virou um problema para o governo, para os indígenas e para a antropologia. A base desse problema era a acusação preconceituosa contra os indígenas de terem deixado de ser indígenas devido à migração para fora dos seus territórios, para as cidades. Segundo estes autores, esse preconceito não leva em conta os processos históricos dos 
povos indígenas. No entanto, os autores utilizam o conceito de "etnogênese" para se referir ao processo dos povos que buscam ser reconhecidos como indígenas e não o são devido aos preconceitos que ignoram as mudanças históricas das suas sociedades.

Albuquerque e Nakashima explicam que é necessário reconhecer esses preconceitos e hierarquias para conseguir políticas públicas que ajudem a reduzi-los e a alcançar os direitos dos povos indígenas. Afirmam, ainda, que embora o multiculturalismo tenha sido um conceito criado para resolver o problema das diferenças culturais, é um instrumento ambíguo, porque pode ser utilizado também como um instrumento de controle dessas diferenças e dos grupos dentro do Estado. Por isso os autores preferem o uso do conceito de "interculturalidade" para reconhecer a diferença de hierarquia entre as culturas (ALBUQUERQUE e NAKASHIMA, 2012).

Porém, o termo "interculturalidade" como solução ao reconhecimento das hierarquias entre povos indígenas e sociedades nacionais é ainda debatido.

Por exemplo, o pesquisador brasileiro Raimundo Nonato Ferreira do Nascimento tentou entender a apropriação do conceito "interculturalidade" na linguagem das escolas indígenas do estado de Roraima. No entanto, o autor explica que, ainda hoje, o conceito de educação intercultural tem diferentes interpretações. Alguns pesquisadores falam da interculturalidade como um projeto político de diálogo entre culturas em situação de igualdade que ainda não acontece por causa da exclusão dos povos indígenas. Contudo, o termo "educação intercultural" já é utilizado para descrever as escolas indígenas na linguagem dos professores, planejadores e organizações indígenas (NASCIMENTO, 2014, p. 19).

Nascimento sugere que a interpretação da "interculturalidade" na América Latina é de origem europeia: enquanto o "multiculturalismo" dos Estados Unidos procurava a participação das minorias, a "interculturalidade" francesa, além de reconhecer a diversidade, defendia a convivência cultural (NASCIMENTO, 2014, p. 249). Essa forma de entender a "interculturalidade" rejeitava o propósito civilizador da educação, exigia o reconhecimento das tradições das identidades, das formas de educação, e os conhecimentos tradicionais indígenas. Uma 
escola baseada nesses propósitos deixaria de ser civilizadora e seria ressignificada para virar uma ferramenta dos direitos e das lutas indígenas (NASCIMENTO, 2014, p. 250). Mas o autor sugere também que a realidade ainda não consegue o propósito que a política intercultural busca. As iniciativas criadas pelas organizações indígenas, comunidades e grupos indigenistas na década de 1970 enfraqueceram com o tempo e viraram uma linguagem utilizada na política que, no entanto, não representa a realidade (NASCIMENTO, 2014, p. 253).

Essa análise coincide com a das autoras Mariana Paladino e Nina Paiva Almeida, que sugerem uma nova forma de entender a escola intercultural, como espaços para construir um conhecimento de fronteira sobre o contato interétnico, que reconheça as políticas identitárias dos povos indígenas e permita esses conhecimentos nas suas línguas. A escola intercultural seria um projeto de conhecimento para mudar as relações de desigualdade desde as propostas políticas dos povos indígenas, desde cada comunidade e suas necessidades do cotidiano, até suas necessidades territoriais e políticas (PALADINO e ALMEIDA, 2012, p. 19). Em outras palavras, a escola deve partir do projeto político dos povos indígenas e ajudar na solução dos problemas políticos de território e de sustentabilidade, além de reduzir a desigualdade histórica entre a sociedade dominante e as sociedades indígenas.

Segundo as autoras, existem avanços positivos dos governos Lula (2003-2010) desde o ensino fundamental até a educação superior, mas essas mudanças, acontecidas tardiamente em comparação com o restante da América Latina, ainda não resolvem os problemas da educação intercultural. Nem o reconhecimento, ainda fraco, das propostas indígenas na política pública, nem a formação dos professores indígenas, nem a aplicação local das políticas nacionais, nem a produção de materiais conseguem o seu propósito de ser interculturais (PALADINO e ALMEIDA, 2012, p. 143).

$\mathrm{Na}$ Colômbia, o propósito de apropriação da escola é defendido por várias organizações indígenas, principalmente pelo Consejo Regional Indígena del Cauca (CRIC). O CRIC afirma que a educação que eles chamaram de "própria" há quarenta e três anos nasceu como um projeto das comunidades indígenas da região do Cauca. O projeto 
procurava uma educação bilíngue que reconhecesse a realidade social e econômica dos povos indígenas. Mas esse projeto educativo só existia dentro da luta pelos seus direitos territoriais e políticos (PEBI CRIC, 2004).

O projeto das organizações indígenas da região do Cauca inspirou muitas outras organizações, inclusive as organizações da região amazônica, mas ali o projeto educativo indígena teve diferenças, porque nasceu de um contexto diferente. Omar Garzón afirma que os povos indígenas amazônicos, principalmente nos rios Apaporis, Caquetá e Mirití, têm uma interpretação diferente dos conceitos de "etnoeducação", "educação própria" e "educação intercultural". Segundo Garzón, a importância que os povos amazônicos atribuem à escola tem quatro causas: manter as crianças perto da comunidade para elas aprenderem os costumes e escutarem os conhecimentos tradicionais, o papel da escola na circulação das mercadorias e do dinheiro na comunidade, na apropriação do conhecimento dos "brancos" e, principalmente, na relação entre a escola e a administração política do território (GARZÓN, 2006, p. 66-76).

Castillo e Rojas acreditam que as políticas da educação chamada de "multicultural" ou "intercultural" existem por causa da pressão das organizações sociais indígenas, mas também disfarçam formas de subordinação dos grupos étnicos (CASTILLO e ROJAS, 2005, p.12). Acreditam que as políticas educacionais reproduzem a ordem social colonialista, onde indígenas e comunidades negras ainda devem ser educados para entrar na nação, mas o reclamo de uma educação própria demonstra a resistência contra essas relações colonialistas (CASTILLO e ROJAS, 2005, p. 138).

Gasché, por exemplo, entende o discurso da educação intercultural como simples discurso da reivindicação dos oprimidos sem conseguir mudar a opressão, porque não leva em conta a forma com que as culturas indígenas são atingidas pela influência histórica das sociedades nacionais dominantes. Por isso, a pedagogia não consegue entender a "alteridade" dos povos indígenas, embora aceite sua existência. Pelo contrário, entender a lógica da vida indígena e a legitimidade de uma vida social diferente permitiria, segundo o autor, criticar o modelo dominante (GASCHÉ, 2010, p. 114). 
É evidente que existem mais autores que enfatizam a reinterpretação e apropriação indígena das escolas do que autores que enfatizam a ação civilizadora da escola, embora isso não demonstre a primeira hipótese. É possível dizer que todos os autores coincidem para afirmar que o projeto político dos povos indígenas, a escola e a educação estão ligados. Mas vale a pena levar em conta a visão pessimista se for para não esquecer de perguntar qual será o resultado dessa relação: "civilização" dos povos indígenas ou "liberação".

Se a apropriação e transformação das escolas em prol dos direitos indígenas está acontecendo há mais de uma década, é legítimo perguntar por que os pesquisadores que a estudam coincidem para dizer que a escola ainda não consegue ser intercultural.

\section{O lugar das crianças indígenas nas sociedades indígenas e fora da escola}

Por que é importante estudar a educação entre os povos indígenas desde o lugar das crianças? É claro que as crianças indígenas e não indígenas têm espaços de aprendizado diferentes da escola. Mas é necessário se perguntar por que as sociedades não indígenas supõem que a escola é o mais importante lugar do aprendizado das crianças e por que a escola parece cada vez mais importante nas sociedades indígenas. Essa pergunta é ainda mais importante, levando em conta que a escola chegou nas aldeias há poucas décadas.

Utilizando a experiência das sociedades indígenas, Tassinari argumenta que existem espaços fora da escola onde as crianças participam da vida social e são mestres e aprendizes ao mesmo tempo, com capacidade de resolver problemas práticos. Utiliza as evidências nos trabalhos antropológicos sobre os povos indígenas do Brasil para afirmar que muitos deles reconhecem a capacidade de compreensão das crianças por causa do lugar delas entre o mundo humano e não humano no pensamento indígena (TASSINARI, 2012b, p. 276). Sugere que é possível entender melhor essas sociedades e até mudar as epistemologias das nossas sociedades se formos capazes de entender melhor essas formas de participação das crianças em outros espaços 
que existem entre os povos indígenas.

No entanto, as sociedades não indígenas estão acostumadas a pensar na infância como um momento sem responsabilidades, limitado pela fantasia e de afastamento da vida social real. Desde esse ponto de vista, a escola retira poder às crianças (TASSINARI, 2012b, p. 291). Limitar a fase da infância pela condição de aluno não só retira as crianças da sua participação na sociedade, mas também limita a aprendizagem na infância, retirando a capacidade de aprender dos adultos (TASSINARI, 2012b, p. 292).

Clarice Cohn é uma das autoras que parece ter tido maior influência na antropologia brasileira no estudo das crianças indígenas e da aprendizagem nos povos indígenas do Brasil. No seu trabalho sobre as crianças xikrim, Cohn defende uma ideia que tem sido recolhida por vários autores: para os adultos xikrim, as crianças sabem tudo, porque têm acesso a ouvir e ver tudo, embora não saibam nada por serem crianças (COHN, 2000).

A aparente contradição dessa afirmação levou a autora a estudar a relação entre aprendizado e concepção das crianças entre os Xikrim. Segundo Cohn, embora existam muitas situações onde as crianças não participam das atividades da sociedade, também existem muitas outras onde têm grande desenvoltura na interação social. Essas formas de se relacionar estabelecem diferenças também em várias dimensões da vida xikirm. Uma delas é a autoridade para falar e compartilhar o conhecimento dos adultos mais velhos, ou para uma criança pedir conhecimento a uma pessoa adulta. Segundo Cohn, para os Xikrim, essa capacidade consciente das crianças de se relacionar, ver e ouvir tudo deve se desenvolver durante a infância até dominar as regras sociais e os conhecimentos relevantes dentro da cultura (COHN, 2000, p. 180).

Baseados em ideias semelhantes, vários autores estudaram o lugar das crianças nas sociedades indígenas para descobrir formas diferentes de educação e aprendizagem.

Leczinieski estudou a centralidade das crianças na vida social do povo Kadiwéu, principalmente, na vida ritual e nos mitos, onde eles são as personagens principais. A autora afirma que as etnografias sobre diferentes povos indígenas do Brasil são evidência de que as crianças têm sempre um lugar central na mitologia, até quando não são o centro 
da pesquisa antropológica (LECZINIESKI, 2012, p. 39). Depois de analisar a mitologia kadiwéu, a autora afirma que as crianças estão sempre no centro da narrativa, por causa da sua relação com outros mundos. Essa relação é necessária para o povo Kadiwéu, porque a origem do "sistema kadiwéu" está baseada nela (LECZINIESKI, 2012, p. 35). Por isso a autora afirma que as crianças são seres "hiperssociais", com uma socialidade diferente e maior do que a dos adultos (LECZINIESKI, 2012, p. 47). Por causa da sua relação com outros mundos e seu processo de incorporação no grupo dos parentes, a criança tem um poder no mundo dos adultos, o que a autora chama de "agência" (LECZINIESKI, 2012. p. 48).

Segundo Codonho, entre os Galibi-Marworno, as crianças têm a responsabilidade de ligar diferentes mundos: o mundo indígena e o mundo não indígena, o mundo humano e o mundo não humano (CODONHO, 2012, p. 60). O papel de mediação das crianças, entre os Maxakali, influi na relação entre a morte e a vida, entre a sociedade indígena e não indígena, mas também no balanço do poder entre homens e mulheres, segundo Álvares (2012).

Outros trabalhos seguem a hipótese de Tassinari das crianças como produtoras de conhecimento. Codonho apresenta a aprendizagem das crianças no povo Galibi-Marworno como uma atividade que acontece o tempo todo na vida social (CODONHO, 2012, p. 72). Oliveira compartilha essa perspectiva na sua interpretação do grupo coral e a atividade da reza como conhecimento produzido, ao mesmo tempo, pelas crianças e pelo professor, diferente do conhecimento escolar transmitido pelo professor e recebido pelas crianças (OLIVEIRA, 2012). Clarissa Rocha de Melo sugere que, para os Guarani, o conhecimento é desenvolvido pelas crianças em uma memória escrita no corpo e na forma delas utilizarem o corpo no cotidiano, sem a transmissão de conhecimentos dos adultos (MELO, 2012).

Alguns outros trabalhos aceitam também a hipótese da produção infantil do conhecimento, mas acham que essa produção acontece na experiência solidária entre as crianças. Nascimento, Urquiza e Vieira pensam que as crianças kaiowá e guarani criam novos significados dentro da cultura influenciando também as relações entre os adultos. Acham que o instrumento principal dessa criação é a brincadeira, 
porque lhes permite desenvolver um lugar identitário e material sem a ajuda dos adultos (NASCIMENTO, URQUIZA e VIEIRA, 2011). Brostolin e Cruz, que estudaram a educação dos Terena no Mato Grosso do Sul, entendem-na como experiência solidária de apropriação de saberes entre adultos e crianças, que permite às crianças acharem sua identidade de gênero e étnica (BROSTOLIN e CRUZ, 2011 , p.177).

No caso das pesquisas na Colômbia, Pachón propõe dar centralidade às crianças na pesquisa antropológica, porque os trabalhos acadêmicos que estudam as crianças ainda priorizam a opinião dos pais, professores e adultos. Pachón analisa o desenvolvimento histórico da pesquisa antropológica sobre a infância e ressalta os resultados do trabalho de Díaz sobre a aprendizagem entre os Cubeo do Rio Vaupés (PACHÓN, 2015).

Diaz, do seu lado, sugere que os pais e as mães cubeo rejeitam proteger as crianças das suas próprias experiências. Pelo contrário, utilizam comparações, metáforas ou perguntas diante das crianças e deixam-nas avaliarem as consequências das suas decisões. Segundo Diaz, dessa forma, as crianças aprendem a partir da criação de conhecimentos próprios e não pela transmissão dos conhecimentos dos adultos (DIAZ, 2010).

Do mesmo modo, Correa estudou a posição social das crianças entre os Cubeo da Amazônia colombiana. Segundo Correa, desde os cinco ou seis anos, as crianças compartilham as tarefas dos pais. Essas atividades se tornarão importantes para sua participação na vida social. Quando as crianças puderem participar da vida produtiva, viram adultas, num ritual que thes prepara para essa vida. Esses ritos são diferentes para mulheres e homens. No entanto, o objetivo principal do rito é a comunicação com os antepassados, por meio das flautas tradicionais de seres que moram no universo. O propósito dessa comunicação é desenvolver a identidade da criança com a comunidade cubeo (CORREA, 2015).

Mas a única dificuldade para entender o lugar das crianças entre os povos indígenas não é o preconceito das sociedades indígenas sobre as crianças como "incompletas". Segundo vários autores, uma das dificuldades da antropologia clássica para entender a construção dessas identidades indígenas das crianças é o conceito da cultura indígena 
como fixa.

O lugar da escola na vida das crianças indígenas e sua relação com as mudanças históricas e econômicas dos povos indígenas

Nessa perspectiva, Brand analisa o enfraquecimento do papel da mulher na educação das crianças entre os Kaiowá e Guarani por causa das mudanças econômicas que obrigam as mulheres a dependerem dos homens e lhes impedem de produzir alimento para as crianças (BRAND, 2011). Gómez, Da Silva e Diniz analisam o processo de mudança da escolarização entre os Pataxó de Carmésia e entre os Xacribá. Estes autores pensam que a escola apresenta formas diferentes em cada sociedade por causa dos diferentes processos históricos da criação da escola nos seus territórios (GOMEZ, DA SILVA e DINIZ, 201 1, p. 263).

Echeverri advertiu sobre a expectativa criada pelo crescimento da cidade e a presença das escolas nas aldeias do Amazonas, o que afastava as mulheres indígenas das atividades importantes da produção dos alimentos para procurar emprego na cidade (ECHEVERRI, 2008).

Bergamaschi interpreta as formas ambíguas da aprendizagem dos Mbyá-Guarani como resultado de mudanças históricas produzidas pela apropriação da escola, que está na fronteira entre transmitir e criar novas relações sociais (BERGAMASCHI, 2011 ). Mubarac Soubrinho afirma que a escola mudou a forma de ser criança entre os Sateré-Mawé, porque impôs o ofício de aluno às crianças e só aceitou papéis sociais específicos que não existem em muitas sociedades indígenas (MUBARAC SOUBRINHO, 2011 , p. 189).

$\mathrm{Na}$ experiência dos povos indígenas dos Andes colombianos, segundo Tattay Bolaños, existe uma contradição entre as leis e as formas de ensino indígenas. Para essa pesquisadora, os povos indígenas rejeitam com frequência as leis que impedem as crianças de trabalhar nos cultivos para irem à escola, porque é assim que as crianças aprendem a solidariedade e entendem a propriedade coletiva da terra (TATTAY BOLAÑOS, 2010).

No caso dos povos indígenas da região entre os rios Amazonas e Orinoco da Colômbia, segundo Calle Alzate, as leis colombianas que 
regulamentam a vida escolar impõem classificações incompatíveis com as dos povos indígenas. A lei estabelece classificações das crianças a partir da idade. Porém, o povo Sikuani, por exemplo, não reconhece a classificação entre crianças, adolescentes e adultos, mas classifica as pessoas pela suas relações sociais e responsabilidades dentro da família e da produção econômica. Segundo Calle Alzate, nesse contexto, é preciso, para os indígenas, que as crianças aprendam o trabalho doméstico e agrícola, mas isso cria uma população infantil e adolescente vulnerável para ser explorada na produção industrial agrícola e narcotráfico na região (CALLE ALZATE, 2010).

Esses estudos poderiam fazer pensar que uma das mudanças produzidas pela escola é o enfraquecimento do desejo dos jovens de continuar as formas da produção econômica indígena. Se isso for verdade, a escola indígena que existe hoje é diferente da desejada "escola indígena intercultural e bilíngue".

Então, vale a pena perguntar se é possível construir esse tipo de escola, embora a escola esteja atrapalhada nessa contradição.

\section{A escola e as contradições da interculturalidade: sem conclusões, mas com propostas}

Depois de analisar a produção antropológica dos últimos anos sobre educação indígena, vale a pena se perguntar o que podemos aprender com ela. Também gostaria de utilizar uma experiência para explicar o que podemos aprender.

Há alguns anos, fiz parte do Grupo de Trabajo Estudiantil Rexistiendo, um grupo de estudantes universitários de graduação e pós-graduação que acompanhava atividades do programa de educação do Consejo Regional Indígena del Cauca (CRIC), a maior e mais antiga organização indígena que existe na Colômbia. Eu tinha oferecido meu tempo para ajudar nas atividades de ensino sobre pedagogia intercultural dentro do programa de educação e eles tinham aceitado minha oferta, me levando para apoiar oficinas sobre pesquisa nas ciências sociais. O programa pedia aos professores escolares, de diferentes grupos étnicos da região, que fizessem um projeto de 
pesquisa dentro da oficina, a partir de uma visão indígena. Mas os professores diziam não saber escrever um projeto de pesquisa e queriam uma oficina sobre isso. Eu expliquei que não poderia fazer uma oficina para explicar as formas indígenas de pesquisar, porque eu não era indígena. Concordamos, então, em fazer uma aula para eu explicar a redação dos projetos de pesquisa acadêmicos e, depois, mais uma para os professores explicarem entre eles as formas de pesquisa indígena.

Depois da minha apresentação, alguns professores indígenas explicaram que a forma de pesquisa dos povos indígenas nasa, guambiano e outros estava baseada na capacidade de se comunicar com as lagoas, o trovão e a montanha. "Mas como acontece essa comunicação?", perguntei, sem saber como seria possível escrever um projeto cuja metodologia fosse "se comunicar com o trovão". Eles responderam: "O único que pode fazer isso, é o xamã. $E$ a forma de fazê-lo é um segredo do xamã". Confuso, perguntei quantos deles eram xamãs. Eles se olharam uns aos outros e responderam: "Ninguém".

Durante os anos seguintes, o grupo de professores continuou seus projetos de pesquisa. Muitos deles com o propósito de resolver problemas da aldeia. No entanto, as pesquisas mantiveram uma perspectiva formal, muito similar com a tradicional forma de pesquisa dos trabalhos de conclusão de curso ou dissertações das universidades convencionais.

Em diferentes momentos, aproveitei essa experiência para abrir debates sobre as contradições entre o propósito de fazer pesquisas na escola baseadas nos modelos de pesquisa universitários e ensinar os conhecimentos tradicionais indígenas. Muitas vezes, achei que os professores gostavam dessa discussão, embora criasse, às vezes, tensões pessoais entre eles. Mas também achei que as lideranças indígenas do CRIC tentavam evitar as discussões.

Por isso, me sinto perto da proposta de Vasco (2002), na Colômbia, e D'Angelis (2012), no Brasil, quando leio os textos desses autores. Segundo parecem dizer, é possível mudar a desigualdade entre a sociedade dominante e as sociedades indígenas criando um espaço de discussão dialética, de aceite das contradições, mas também de debate entre essas contradições. Esse debate deve acontecer com consciência de que as ideias indígenas foram rejeitadas historicamente, mas não por 
isso foram erradas; de que muitos conhecimentos indígenas têm sido esquecidos por causa dessa rejeição (CAVIEDES, 2015).

No entanto, a criação desse espaço é muito difícil, porque essa discriminação continua funcionando na cabeça das lideranças, da comunidade, dos professores e, com tempo, chega nas cabeças das crianças. E existe medo de participar desse debate com desvantagem.

Isso não é um motivo para desistir dessa proposta, mas é um motivo para procurar outras soluções que ajudem.

Uma dessas soluções, acredito, é colocar mais esforços fora da escola: a antropologia precisa aprofundar nas formas indígenas de educação fora da escola e os povos indígenas precisam maior confiança nessa educação não escolar. Por enquanto, os povos indígenas estão investindo a maioria dos esforços na transformação e reconstrução das escolas. Mas é possível que a solução para a sobrevivência dos conhecimentos indígenas não esteja na escola.

Propor desistir das escolas parece errado, porque as organizações indígenas exigem escolas como parte dos direitos dos povos e das crianças indígenas. Sem dúvida, a escola ajuda na formação das lideranças indígenas, que precisam ler as leis, conhecer a matemática e adquirir conhecimentos para defender seus povos dos abusos dos governos. Mas parece absurdo acreditar que o único esforço deve ser ensinar o conhecimento universal aos indígenas para se defender, como se fosse natural que a sociedade não indígena os engane e explore.

Um dos desafios da antropologia é mudar a sociedade chamada de "dominante" para parar de enganar e explorar os povos indígenas, destruir preconceitos e reduzir a ignorância que sustenta a exploração dos povos indígenas. Esse trabalho deve ser feito, principalmente, em escolas não indígenas.

Outro desafio é apoiar as formas de aprendizado indígena que ainda existem fora da escola, mas que estão enfraquecendo conforme a escola se torna o foco da atenção das expectativas indígenas e acadêmicas. $O$ aprendizado das formas de produção agrícola na região dos Andes e da Amazônia, e na América Latina toda, e a narração das tradições mitológicas nas malocas dos povos indígenas da Amazônia venezuelana, colombiana, peruana e brasileira, por exemplo, são cenários de ensino tão importantes quanto as escolas. 
Limitar os esforços para estudar ou apoiar as escolas seria esquecer que a luta pela educação indígena acontece na própria sobrevivência desses conhecimentos, não em mudá-los para serem aceitos nas escolas.

\section{Referências bibliográficas}

ALBUQUERQUE, Marco Alexandre dos Santos; GRANDO, B. S. Apresentação. In: TASSINARI, A. M. I.; GRANDO, B. S.; ALBUQUERQUE, Marco Alexandre dos Santos (Org.). Educação indígena: reflexões sobre noções nativas de infância, aprendizagem e escolarização. Florianópolis: Editorial da UFSC, 2012. p. 7-15.

ALBUQUERQUE, Marco Alexandre dos Santos; NAKASHIMA, E. Y. Consenso e dissenso: os Pankararu e a educação intercultural na cidade de São Paulo. In: TASSINARI, A. M. I.; GRANDO, B. S.; ALBUQUERQUE, Marco Alexandre dos Santos (Org.). Educação indígena: reflexões sobre noções nativas de infância, aprendizagem e escolarização. Florianópolis: Editorial da UFSC, 2012. p. 197-222.

ALVARES, M. M. Criança e transformação: os processos de construção de conhecimento. In: TASSINARI, A. M. I.; GRANDO, B. S.; ALBUQUERQUE, Marco Alexandre dos Santos (Org.). Educação indígena: reflexões sobre noções nativas de infância, aprendizagem e escolarização. Florianópolis: Editorial da UFSC, 2012. p. 7792.

BATESON, M. C. Como yo los veía: Margaret Mead y Gregory Bateson Recordados por su Hija. Buenos Aires: Gedisa Editorial, 2004.

BERGAMASCHI, Maria A. A criança guarani: um modo próprio de aprender. In: NASCIMENTO, A., URQUIZA, A.; VIEIRA, C. (Org.). Criança indígena: diversidade cultural, educação e representações sociais. Brasília: Liber Livro Editora Ltda, 2011. p. 131-156.

BRAND, Aantonio. A criança kaiowá e guarani em contexto de rápidas mudanças-uma abordagem histórica. In: NASCIMENTO, A., URQUIZA, A.; VIEIRA, C. (Org.). Criança indígena: diversidade cultural, educação e representações sociais. Brasília: Liber Livro Editora Ltda, 2011. p. 113-130.

BROSTOLIN, M. R.; CRUZ, S. D. F. Criança Terena - algumas considerações a respeito de suas representações identitárias e culturais. In: NASCIMENTO, A., URQUIZA, A.; VIEIRA, C. (Org.). Criança indígena: diversidade cultural, educação e representações sociais. Brasília: Liber Livro Editora Ltda, 2011. p. 157-180.

CALLE ALZATE, L. Para la erradicación del trabajo infantil en la Orinoquía. In: 
CORREA, F. (Org.). Infancia y Trabajo Infantil Indígena en Colombia. Bogotá: Universidad Nacional de Colombia/OIT, 2010. p. 199-256.

CASTELLANOS, M., CAVIEDES, Mauricio. La educación en los pueblos indígenas de Colombia. In: REY, Elena (Org.). Indígenas sin derechos: situación de los derechos humanos de los pueblos indígenas. Informe 2007. Bogotá: CECOIN-OIA, 2007.

CASTILLO, E.; ROJAS, A. Educar a los otros. Estado, políticas educativas y diferencia cultural en Colombia. Popayán: Editorial Universidad del Cauca, 2005.

CAVIEDES, Mauricio. El debate sobre la educación escolar indígena: posibilidades desde el análisis antropológico. In: CAVIEDES, Mauricio; DÍAZ, M. (Org.). Infancia y Educación: análisis desde la antropología. Bogotá: Editorial Pontificia Universidad Javeriana, 2015.

CODONHO, Camila G. Cosmologia e infância Galibi-Marworno: aprendendo, ensinando, protagonizando. In: TASSINARI, A. M. I.; GRANDO, B. S.; ALBUQUERQUE, Marco Alexandre dos Santos (Org.). Educação indígena: reflexões sobre noções nativas de infância, aprendizagem e escolarização. Florianópolis: Editorial da UFSC, 2012. p. 53-76.

COHN, Clarisse. A criança indígena: a concepção Xikrim de infância e aprendizado. 2000. 187 f. Dissertação (Mestrado em Antropologia) - Programa de Pós-Graduação em Antropologia, Universidade de São Paulo, São Paulo, [2000]. Disponível em: http://www.ced.ufsc.br/ nee0a6/cohndiss.pdf. Acesso em: 16 fev. 2014.

CORREA, F. La construcción del Ser y el Poder de los ancestros entre los Cubeo. In: CAVIEDES, Mauricio; DÍAZ, M. (Org.). Infancia y Educación: análisis desde la antropología. Bogotá: Editorial Pontificia Universidad Javeriana, 2015. p. 53-95.

D'ANGELIS, W. D. R. Aprisionando sonhos: a educação escolar indígena no Brasil. Campinas: Curt Nimuendajú Editora, 2012.

DÍAZ, M. La exploración asistida: orientación del conocimiento en la educación inicial de indígenas Cubeo del Amazonas. In: DÍAZ, M.; VÁSQUEZ, S. (Org.). Contribuciones a la antropología de la infancia: la niçez como campo de agencia, autonomía y construcción cultural. Bogotá: Pontificia Universidad Javeriana, 2010.

DURKHEIM, E. Las formas elementales de la vida religiosa: el sistema totémico en Australia. Madrid: Editorial Akal. 1992 [1912].

ECHEVERRI, J. A. ¿De chagrera a secretaria?: Balance de algunas acciones en etnoeducación en el Amazonas colombiano. In: BERTELY, M.; GASCHÉ, J.; PODESTÁ, R. (Org.). Educando en la diversidad: investigaciones y experiencias educativas interculturales y bilingües. Quito: Abya-Yala, 2008. p. 135-166.

GARZÓN, O. Educación, escuela y territorio en las regiones de los ríos Medio y Bajo Caquetá, Mirití y Bajo Apaporis. In: GARZÓN, O. (Org.). Educación, Escuela y 
Territorio en la Amazonía Colombiana. Bogotá: Fundación Gaia Amazonas, 2006. p. 21-86.

GASCHÉ, Jorge. De hablar de educación intercultural a hacerla. Mundo Amazónico, v. 1, p. 111-134, 2010.

GOBBI, I. O que os livros didáticos dizem sobre os povos indígenas? In: TASSINARI, A. M. I.; GRANDO, B. S.; ALBUQUERQUE, Marco Alexandre dos Santos (Org.). Educação indígena: reflexões sobre noções nativas de infância, aprendizagem e escolarização. Florianópolis: Editorial da UFSC, 2012. p. 223-246)

GOMES, A. M. R.; DA SILVA, R. C.; DINIZ, L. Infância indígena, escolarização e globalização: uma análise a partir da experiência das escolas indígenas em Minas Gerais. In: NASCIMENTO, A., URQUIZA, A.; VIEIRA, C. (Org.). Criança indígena: diversidade cultural, educação e representações sociais. Brasília: Liber Livro Editora Ltda, 2011. p. 227-268.

GRANADOS, D.; CAVIEDES, M. El reconocimiento abstracto del derecho a la educación de los pueblos indïgenas de Colombia. Señas,. Bogotá, n. 1, p. 95-106, 2011.

GROS, C. Colombia Indígena. Bogotá: CEREC, 1991.

GUTIÉRREZ, S. Algunos caminos de la educación propia: notas para entender el programa de educación del COTAINDOC. In: CAVIEDES, Mauricio; DÍAZ, M. (Org.). Estudios antropológicos sobre la diversidad, la infancia y la educación. Bogotá: Pontificia Universidad Javeriana, 2015. p. 171-200.

JACKSON, J. Preserving indian culture: chaman schools and ethoeducaction in the Vaupés, Colombia. Cultural anthropology, v. 10, n. 3, p. 302-329, 1995.

JESUS, S.C.D. Acampamentos indígenas no sul do Brasil: os diversos olhares para a educação e a infância Mbyá-Guarani. In: TASSINARI, A. M. I.; GRANDO, B. S.; ALBUQUERQUE, Marco Alexandre dos Santos (Org.). Educação indígena: reflexões sobre noções nativas de infância, aprendizagem e escolarização. Florianópolis: Editorial da UFSC, 2014. p. 141-162.

KUPER, A. Cultura, la versión de los antropólogos. Barcelona: Paidós. 2002.

LECKZINIESKI, L. Seres hipersociais: A centralidade das crianças na mitlogia, nos rituais e na vida social dos povos sul-ameríndios. In: TASSINARI, A. M. I.; GRANDO, B. S.; ALBUQUERQUE, Marco Alexandre dos Santos (Org.). Educação indígena: reflexões sobre noções nativas de infância, aprendizagem e escolarização. Florianópolis: Editorial da UFSC, 2012. p. 25-52.

LEVI-STRAUSS, Claude. El pensamiento Salvaje. Bogotá: Fondo de Cultura Económica, 1997 [1962].

LIMA, Antônio Carlos de Souza, BARROSO-HOFFMAN, M.; PERES, S. C. Notas 
sobre os antecedentes históricos das idéias de "etnodesenvolvimento" e de "acesso de indígenas ao ensino superior" no Brasil. Roraima: Laboratório de Pesquisa em Etnicidade, Cultura e Desenvolvimento, s.d. Disponível em: http://www.trilhasdeconhecimentos.etc.br/artigos/arquivos/Texto_Etnodesenvolvimento _e_Ensino_Superior_Indigenas.pdf. Acesso em: 16 fev. 2014.

MAHECHA, D. Leer y escribir "Brujería de Blanco": Los procesos de escolarización en el Bajo Apaporis. In: GARZÓN, O. (Org.). Educación, Escuela y Territorio en la Amazonía Colombiana. Bogotá: Fundación Gaia Amazonas, 2006. p. 185-214.

MAHECHA, D.; FRIERI, S. Transiciones escolares en contextos multiculturales: de la secundaria a la educación superior, dos casos de estudio en el Amaznas colombiano. In: MAHECHA, D. (Org.) La Educación Superior en la Amazonia hoy: Inclusión, pertinencia y financiación en los programas de formación. Leticia: Universidad Nacional de Colombia Sede Amazonia/Instituto Amazónico de Investigaciones IMANI, 2011. p. 161-179. Disponível em: http://www.bdigital.unal.edu.co/6396/. Acesso em 25 jul. 2014.

MALINOWSKI, B. The dynamics of cultural change: an inquiry into race relations in Africa. London: Oxford University Press, 1949.

MEAD M. Comming of age in Samoa: a Psychological study of primitive youth for western civilization. New York: Mentor Books, 1949 [1928].

MELO, C. R. D. Uma escuta do mundo: processos de ensinar e aprender entre os Guarani. In: TASSINARI, A. M. I.; GRANDO, B. S.; ALBUQUERQUE, Marco Alexandre dos Santos (Org.). Educação indígena: reflexões sobre noções nativas de infância, aprendizagem e escolarização. Florianópolis: Editorial da UFSC, 2012. p. 117140 .

MUBARAC SOBRINHO, R. S. Os saberes da "escola do branco" e as culturas das crianças indígenas: uma prática pedagógica dos (des)encontros. In: NASCIMENTO, A.; URQUIZA, A.; VIEIRA, C. (Org.). Criança indígena: diversidade cultural, educação e representações sociais. Brasília: Liber Livro Editora Ltda, 2011. p. 181-204.

MUSGROVE, C. Anthropology and education: other cultures and the teacher. London: Louis and sons Inc., 1982.

NASCIMENTO, A.; URQUIZA, A.; VIEIRA, C. A cosmovisão e as representações das crianças kaiowá e guarani: o antes e o depois da escolarização. In: NASCIMENTO, A.; URQUIZA, A.; VIEIRA, C. (Org.). Criança indígena: diversidade cultural, educação e representações sociais. Brasília: Liber Livro Editora Ltda, 2011. p. 21-44.

NASCIMENTO, Raimundo Nonato Ferreira do. Interculturalidade e Educação escolar indígena em Roraima: da normatização à prática cotidiana. 2014. $264 \mathrm{f}$. Tese (Doutorado em Antropologia) - Universidade Federal de Pernambuco, CFCH. Programa de Pós-graduação em antropologia, [2014]. 
OLIVEIRA, M. S. D. Nhanhembo'é: infância, educação e religião entre os Guarani de M'Biguaçu, SC. In: TASSINARI, A. M. I.; GRANDO, B. S.; ALBUQUERQUE, Marco Alexandre dos Santos (Org.). Educação indígena: reflexões sobre noções nativas de infância, aprendizagem e escolarização. Florianópolis: Editorial da UFSC, 2012. p. 93116.

PACHÓN, X. Los estudios sobre infancia y la antropología colombiana: una aproximación. In: CAVIEDES, M.; DÍAZ, M. (Org.). Estudios antropológicos sobre la diversidad, la infancia y la educación. Bogotá: Pontificia Universidad Javeriana, 2015. p. 21-53.

PALADINO, M.; ALMEIDA, N. P. Entre a diversidade e a desiguadade: uma análise das políticas públicas para a educação escolar indígena no Brasil dos governos Lula. Rio de Janeiro: Museu Nacional/UFRJ/LACED, 2012.

PEBI - CRIC. Que pasaría si la escuela...?: 30 años de construcción de una educación propia. Programa de Educación Bilingue e intercultural. Bogotá: Editorial Fuego Azul, 2004.

PEREIRA, L. M. A socialização da criança kaiowá e guarani: formas de socialidade internas às comunidades e transformações históricas recentes no ambiente da vida. In: NASCIMENTO, A.; URQUIZA, A.; VIEIRA, C. (Org.). Criança indígena: diversidade cultural, educação e representações sociais. Brasília: Liber Livro Editora Ltda, 2011. p. 75-112.

REZENDE, J. S. Crianças Indígenas de Iauareté: Fortalecimento das identidades e diferenças. In: NASCIMENTO, A.; URQUIZA, A.; VIEIRA, C. (Org.). Criança indígena: diversidade cultural, educação e representações sociais. Brasília: Liber Livro Editora Ltda, 2011. p. 269-284.

ROJAS CURIEUX, T. En la reflexión sobre lo oral y lo escrito: educación escolar y práctica en pueblos indígenas. Popayán: Editorial Universidad del Cauca, 2005.

ROSALDO, R. Cultura y verdad, la reconstrucción del análisis social. Quito: AbyaYala, 2000.

TASSINARI, A. M. I. Introdução: Sobre noções nativas e antropológicas em educação indígena. In: TASSINARI, A. M. I.; GRANDO, B. S.; ALBUQUERQUE, Marco Alexandre dos Santos (Org.). Educação indígena: reflexões sobre noções nativas de infância, aprendizagem e escolarização. Florianópolis: Editorial da UFSC, 2012a. p. 1524.

A sociedade contra a escola. In: TASSINARI, A. M. I.; GRANDO, B. S.; ALBUQUERQUE, Marco Alexandre dos Santos (Org.). Educação indígena: reflexões sobre noções nativas de infância, aprendizagem e escolarização. Florianópolis: Editorial da UFSC, 2012b. p. 275-294.

A educação escolar indígena no contexto da antropologia brasileira. Ilha, 
Florianópolis, v. 10, p. 217-244, 2009.

Escola indígena: novos horizontes teóricos, novas fronteiras de educação. In: DA SILVA, A. L.; FERREIRA, Mariana (Org.). Antropologia, História e Educação: A questão indígena e a educação. São Paulo: Editora Global, 2001. p. 45-70.

TASSINARI, A. M. I.; COHN, Clarisse. Escolarização indígena entre os Karipuna e Mebengokré-Xikrin: uma abertura para o outro. In: TASSINARI, A. M. I.; GRANDO, B. S.; ALBUQUERQUE, Marco Alexandre dos Santos (Org.). Educação indígena: reflexões sobre noções nativas de infância, aprendizagem e escolarização. Florianópolis: Editorial da UFSC, 2012. p. 247-274.

TATTAY BOLAÑOS, L. Niños y niñas del Cauca Indígena. In: CORREA, F. (Org.). Infancia y Trabajo Infantil Indígena en Colombia. Bogotá: Universidad Nacional de Colombia/Organización Internacional del Trabajo. 2010. p. 151-198.

VASCO, L. G. Entre selva y páramo: viviendo y pensando la lucha india. Bogotá: ICANH, 2002.

WOLF, Eric. Europe and the peoples without history. Berkeley: University of California Press, 1982. 